\title{
Development of didactic materials and activities on interdisciplinary bases: an example for oil and gas
}

\author{
José SelLés-Martínez \\ Dpto. de Ciencias Geológicas, Fac. de Ciencias Exactas y Naturales, Universidad de Buenos Aires \\ Pabelón 2, Ciudad Universitaria, 1428, Buenos Aires, Argentina \\ EMAIL: PEPE@GL.FCEN.UBA.AR
}

Abstract: Although the subject "Oil and Gas" is not usually present in the Secondary School Curriculum, it is of interest to students due to its obvious relationships with everyday life, and has been selected to design a series of teaching resources. Not only natural sciences such as Geology, Biology and Chemistry are embedded in the formation and accumulation of petroleum, but also constant references to History, Geography and Technology are present when linking together its discovery, exploitation, industrialization and use. The materials being produced cover three categories: a reference text to be available in printed and PDF file versions, a portfolio of teaching resources and a website. The first two are described and exemplified. The portfolio also includes examples of published materials, which contain conceptual errors proposing their use to explore misconceptions if used at the beginning of the presentation of the subject in class, or to identify levels of understanding if used at the end.

\author{
Manuscript: \\ Recebido: Quadrennial Conference of the International \\ Geoscience Education Organization \\ Aceito: 24/06/2018 \\ Citation: Sellés-Martínez J. 2018. Development of \\ didactic materials and activities on interdisciplinary \\ bases: an example for oil and gas. Terræ Didatica, \\ 14(3):256-262. URL: http://www.ige.unicamp.br/ \\ terraedidatica/. \\ Keywords: Petroleum Geology, Chemistry, interdisci- \\ plinarity, misconceptions \\ Thematic line: Teaching of Geosciences and Natural \\ Sciences for School-Level Education and Teacher \\ Training
}

\section{Introduction}

It is not novelty that the teaching and learning of science (even of natural sciences, such as Geology), is always facilitated by the use of interdisciplinary links and socio-historical frameworks. Anyway, it is not easy for teachers to investigate, design and test their own materials on a given subject, since this task is very time-consuming and time is something that teachers do not have enough. The Dpt. of Geology of the University of Buenos Aires has a long tradition in the area of outreach and production of didactic materials and activities, mainly (but not exclusively) through the Aulagea program (Sellés-Martínez 2013) and, from most recent times on, the J.J. Nágera Program, nested in the Instituto de Geociencias Básicas, Aplicadas y Ambientales de Buenos Aires (IGEBA). A recent call from the University of Buenos Aires, offered the author and collaborators an opportunity for funding a research project that could result in new educational resources based both on traditional and new technologies that, necessarily, had to be interdisciplinary. Our proposal, named "Oil and gas: production of materials and strategies for an interdisciplinary and contextualized teaching, aimed at secondary schools and teacher training levels", was successful in obtaining some funds, and the present paper offers a brief description of its fundamentals and the materials that are being produced, along with several suggestions about how to use them. These materials should be freely available for teachers and students at an interactive platform available at a website in the Internet. A set of printed booklets and a portfolio with teaching resources is also under preparation, specifically aimed at teacher-training workshops and work in class.

The main idea was to link basic concepts involved in the word "Petroleum" or "Oil and Gas", to more detailed information coming from Geology, Chemistry, Biology and Physics, and also to history of mankind and technology, without forgetting relevant aspects of societal use of natural resources and sustainable development. The goal was to positively impact in the formation of students (that will soon became active citizens) in subjects that

\begin{tabular}{l|l|l|l|l|l}
\hline 256 (C) Terrae Didat. & Campinas, SP & v.14 & n.3 & p. 256-262 & jul./set. 2018 \\
\hline
\end{tabular}


are of primary importance in almost every society (as use of natural resources, fracking practices and the like) and that require being well informed at the time of voting. This is important indeed because the subjects to be addressed are not usually well known and people may be misled when giving opinions on them.

\section{The starting point}

"Oil and Gas" is almost ignored as a subject to be learned in most of the Science Curriculums of the different educational jurisdictions of Argentina. This fact is actually astonishing if we take into consideration that Argentina has been an oil and gas producer for more than a century and is now entering exploitation of non-conventional reservoirs, not to mention that the use of hydrocarbons is of central importance in present life. On the contrary, the results of some educational investigations have rendered clear that there is interest in the subject from science teachers and from many students (Galagovsky y Pergola, 2017 among others). On the other side, terms and concepts like rational use of energy, sustainable development, natural resources and protection of the environment are frequently present in other areas of the Curriculum, different from Natural Sciences or Chemistry. This paradox results in the fact that these subjects are difficult to teach and to learn.

The most relevant problems to solve are the facts that: a) The information is dispersed and isolated in different areas of the curriculum. b) When mentioned, these subjects are presented in oversimplified ways, with slogans and common places, and with no reference to their intrinsic complexity or to contextual frames. c) The Chemistry involved is usually canonical and boring and limited to the classification of hydrocarbons. d) Due to the fact that Earth Sciences are almost absent from most of the Primary and Secondary School Curriculums in Argentina (IGEO/UNESCO, in preparation), the geological aspects of oil and gas formation, trapping and exploitation are obviously missing in the formation of students, and, consequently, cannot be linked to related subjects in other areas of the curriculum. From the point of view of the use of not-so-new technologies, they offer the opportunity to generate material that can be offered to a greater number of people, and therefore justifies the effort of producing new materials, no matter their cost in time, human and economic resources.

\section{The on-going results}

Although up to the moment that this paper is being written the final products of the project (a reference text, a portfolio of resources and the website) are not finished and have achieved different stages of development, they will be described in the following paragraphs as they are projected, with references to their aims and principal features, and the use of finished items as examples. Only the printed materials will be addressed with certain detail in this contribution, leaving the description of the website for a future report.

\section{The reference text}

An important effort in searching for information and illustrations and in processing the findings, along with "intensive use" of the authors experience, knowledge and materials had to be carried out, in order to complete with short, clear and conceptually correct texts and figures the Table of Contents summarized below. Preparation of illustrations and searching for those that have no copyright protection required a great amount of time. The fact that the material is designed for non-academic users precluded the use of quotations that are not useful to the unfamiliar reader and produce loss of continuity and dispersion, which hinders comprehension. In the case of hydrocarbon chemistry, the approach was to use very simple texts, starting from atoms and their symbolization and going to molecules and their representation, using different approaches (chemical name, chemical formulae and different graphical models). In the case of basic and petroleum related geology, the use of jargon was minimized and, when possible, the terms were explained in the immediately following lines. The table of contents covers the following items:

Introduction: Petroleum in the history of mankind. Oil and the civilizations of Mesopotamia. Oil in America. Extraction and uses of oil and its derivatives since the 19th century. Drilling in search of oil. Beginnings of the petrochemical industry. Natural gas as fuel.

$1^{\text {st }}$ Part: Hydrocarbons from the point of view of Organic Chemistry. The sub-microscopic and symbolic chemical world. The carbon atom, the bonds between them and the compounds that are formed: alkanes, alkenes, alkynes and aromatics. Alkanes. Alkenes. Alkynes. Aromatic compounds. Molecules formed only by carbon atoms. Fossil 
fuel hydrocarbons. Gas hydrocarbons. Petroleum hydrocarbons. Oxidation of carbon compounds: combustion of hydrocarbons. The oxidation states of carbon compounds. Combustion is a chemical reaction of oxidation. The distillation of oil.

$2^{\text {nd }}$ Part: Fundamentals of Petroleum Geology. Sediments and rocks. Sedimentary basins. Fluids in the subsoil. Porosity and permeability of sedimentary materials. The formation of Oil. Hydrocarbon basins. Hydrocarbon basins of Argentina. Brief history of the discovery of hydrocarbons in Argentina.

$3^{\text {rd }}$ Part: The petroleum system. Concept of source rock. Migration through the subsurface. Concept of reservoir rock. Discontinuities in the subsurface. The seal concept. The trap concept. Unconventional reservoirs.

$4^{\text {th }}$ Part: Some additional topics related to hydrocarbons. Natural hydrocarbon seeps, natural mummifiers. Clathrates, the burning ice. Environmental problems associated with the oil industry. Environmental protection and sustainability. Induced hydrofactures.

$5^{\text {th }}$ Part: Supplementary materials useful for teaching the subject. Some widespread conceptual errors on its origin and accumulation. Activities to reinforce the concepts of porosity and permeability. A selection of illustrations that have errors about the origin and accumulation of oil and gas. (This Part is attached to the reference text as a portfolio in order to make it handier).

In the following paragraphs, the first paragraphs of the Introduction are transcribed in order to exemplify how the subject can be linked to the history of religion, science, technology and also decorative arts and everyday life in the past.

\section{Petroleum in the history of mankind}

References to bitumen or asphalt, substances that are closely related to petroleum, are present since remote times. The Bible describes (among other mentions) how the kings of the cities located in the Dead Sea Rift (Sodom and Gomorrah included), when trying to escape from other kings after being defeated in a battle, fall trapped in the abundant bitumen lakes of the Siddim Valley. The destruction of Sodom and Gomorrah (see Figure 1) took place later on and, according to the Holy Book, it was caused by the fall of Sulphur and Fire from the sky. Several present day researchers have pointed that the destruction could have been

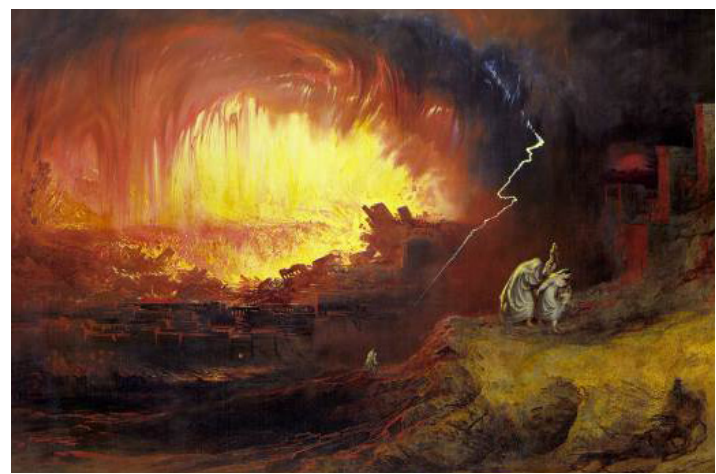

Figure 1. Destruction of the cities of Sodom and Gomorrah as envisaged by John Martin in 1852 (Laing Art Gallery, Newcastle, UK, public domain)

caused by an earthquake or by a meteorite impact. Others go further and propose that some extraordinary event, like the fall of incandescent fragments of a meteorite, could have ignited the bitumen in the ponds and thus triggered a great catastrophe. It is important to consider that, together with accidental blowouts of oil wells, natural fires are a common feature affecting both carbon layers and natural gas vents. These fires can cover very large areas and last for a long time. An extraordinary example of this is the Mount Wingen case, in Australia. According to experts in this case, called "the burning mountain", the carbon layer has been burning for 6,000 years and is extending through the underground at a speed of $1 \mathrm{~m}$ per year. It is important to underline here that, until the 18th Century, the burning and subsequent explosions of carbon or sulphur rich layers was invoked as the possible cause of earthquakes.

\section{Petroleum and the Mesopotamian civilizations}

In the area drained by the Tigris and Euphrates rivers, the use of bitumen has been documented as far back as 7,000 years ago. The people at that time used bitumen to glue the arrow tip to the shaft and also to glue mosaic pieces to a wooden base (The Standard of Ur, see figure 2). Later on, Sumerians used bitumen as mortar to keep bricks attached to each other in their buildings (something that was mentioned by Herodotus and Strabo and which has been confirmed by archaeology). The Bible mentions that the bricks in the Tower of Babel (which Herodotus assures he saw before its destruction) where joined together with bitumen. Babel was the favourite city of the king Nebuchadnezzar, its builder, and many buildings in the city used bitumen as mortar and also to make porous surfaces impermeable.

\begin{tabular}{l|l|l|l|r|r}
\hline 258 C Terrae Didat. & Campinas, SP & v.14 & n.3 & p. 256-262 & jul./set. 2018 \\
\hline
\end{tabular}




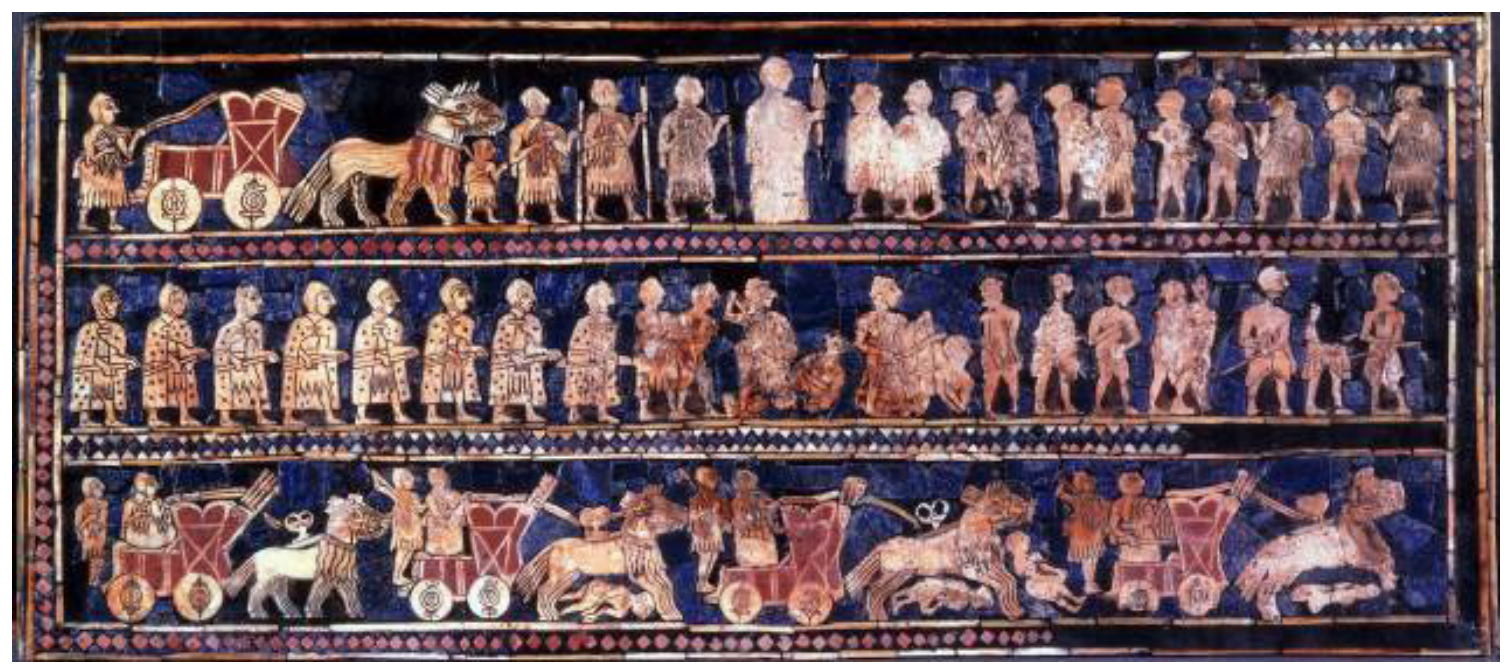

Figure 2. The so-called "Standard of Ur" (2500 BC), combines lapis lazuli, mother of pearl and other stones glued to the wooden support with bitumen (Image from https://commons. wikimedia.org)

Bitumen was also used for paving and to join stones in important roads, but, paradoxically, people then did not take advantage of the burning capability of liquid oils, or of the products resulting from the distillation of bitumen, an achievement that was only developed by the Acadians that entered the region in the $22^{\text {nd }}$ Century BC. The everyday word "naphtha" ("nafta" in Spanish) is of Acadian origin and was introduced to the western languages from its Arabic use, to describe the distillates of bitumen.

The wealth of the kingdom of the Nabateans, which lasted from the $4^{\text {th }}$ Century BC to the $1^{\text {st }}$ Century AC, was partly related to the trade of bitumen. One of their most important clients were the Egyptians, who strongly relied on the use of bitumen not for building (stone pieces are not joined with any mortar in Egyptian architecture) but for the common practice of mummification, which required asphalt, until the time when vegetal resins become extensively used, about $3^{\text {rd }}$ Century BC.

Commercial exploitation of oil seeps in the Dead Sea region has been cited by many historians. In the year $50 \mathrm{AC}$, a Greek historian called Diodorus of Sicily mentions that the richness that the oil trade generates is of real importance, and describes how oil and bitumen deposits form in a regular way. The start of the process is announced about three weeks in advance by the presence of very odorous vapours that the wind carries to cities along the coast, where metallic objects lose their brightness. Several days after this happens, layers of bitumen form on the surface of the water and are driven to the coast by the wind. The probable presence of sulphur compounds (like sulphurous acid and hydrogen sulphide) in the air would explain the chemical attack to metals like silver, which is rapidly covered with a black patina of silver sulphide.

Greeks made intensive use of bitumen and their distillates. They covered the porous interior surface of amphorae with bitumen, to make them impermeable and usable for transporting olive oil and wine. In the times of Byzantium, oil distillates were used to produce the so-called "Greek fires" or "Marine fires" (see Figure 4), which consisted of ignited fluids projected (sometimes with the use of pressure pumps) onto the enemy fleet to set it afire. This technologically revolutionary weapon of the time not only had a great destructive efficiency but also the extraordinary property of continuing

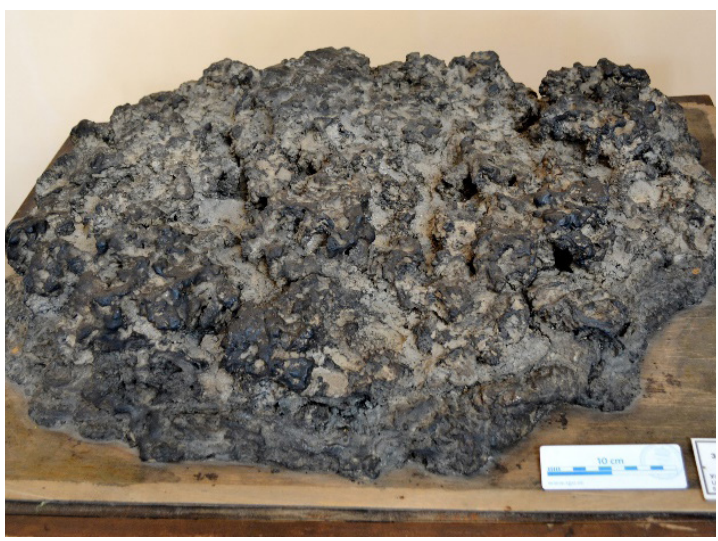

Figure 3. A piece of solid bitumen from Uzbekistan exposed in the Museum of the Geological Institute in Saint Petersburg (Russia). 


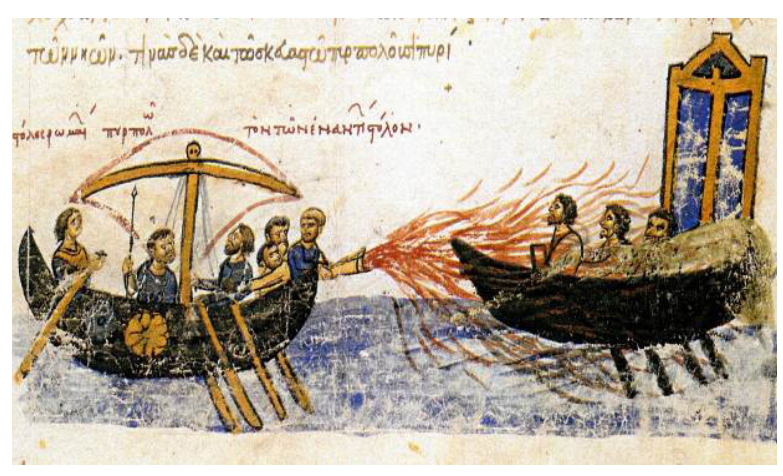

Figure 4. The Greek fires as depicted in a manuscript from Byzantium, (Image: Codex Skylitzes Matritensis, Biblioteca Nacional de Madrid, https://commons. wikimedia.org)

to burn on the water, which, at the time, was supposedly related to witchcraft. They were also called "Roman fires" by the Arabs at the time of the Crusades, when they were extensively used.

Advanced processes of distillation of bitumen and oil were most likely developed by the Arabs, from which the technique then passed to Byzantium, and is intensively used in the development of attack and defence weapons. The Muslim army had soldiers especially trained and equipped with burning weapons, wearing fireproof suits and equipped with the ancestors of today's grenades, as early as the $9^{\text {th }}$ Century.

\section{Petroleum in America}

The presence of natural petroleum and bitumen seeps and lakes was known to many peoples in the Americas, well before the arrival of Columbus. The Olmecas used bitumen to glue and also to make surfaces impermeable, harvesting it from inland seeps, but also from nodules brought to the seashore by waves. The word "chapapote", used at present to describe the residues resulting from oil spills at shipwrecks (which float in seawater and cause enormous ecological damages when they reach the shore, driven by waves, see Figure 5 ), refers to the result of natural distillation of oil which accumulated in depressions.

Spanish chronicles mention the presence of natural seeps and the use of oil and bitumen by the people of Antilles, Mexico, Colombia, Venezuela and Peru. Native tribes from Northeast USA also were aware of natural seeps, and it was their knowledge and use that later resulted in the exploitation of oil in the region.

\section{The portfolio of teaching resources}

Along with the main reference text, a handful of teaching resources will be published (on paper and as PDF files) that can help in the preparation of classes and development of teaching strategies. These resources include some excerpts from media, cartoons and published articles and illustrations that reflect misconceptions.

Figure 6 provides a clear example of an illustration with conceptual errors and misconceptions, which is proposed to be used for discussion in class. A suggested way for using this picture is to carefully observe it and describe what it represents. The fact that it contains mistakes may or may not be mentioned in advance to the students, depending on their level of knowledge or on the objectives of the teacher. Questions that can help identify the errors may be: What is the definition of Earth Crust? Can sedimentary layers be found below it? Why were the upper and lower surfaces of the oil layer drawn horizontally and not following any sedimentary surface? Is shale an impermeable or permeable rock? A lithological trap to catch oil and gas requires the presence of a seal, that is, an impermeable rock, but is the presence of an impermeable rock at the base of the water-oil-gas deposits necessary? How do oil and gas accumulate in economically exploitable quantities? Can they circulate to accumulation areas from the source rock through impermeable materials? Is it possible for water, oil and/ or gas to accumulate in large voids underground or do they just fill small pores between grains in sedimentary rocks? What can you say about the relative sizes of the drilling rig, the Earth's Crust and the depth to the oil layer?

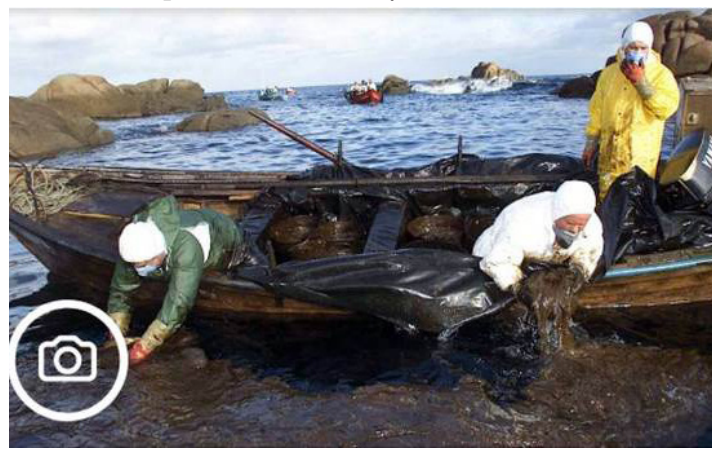

Figure 5. Spanish fishermen collect the "chapapote" from a spill after a shipwreck in the coast of Galicia (https:/elpais.com/elpais/2017/11/10/ album/1510336476_790173.html\#1510336476 _790173_1510566180)

\begin{tabular}{|l|l|l|l|l|l|}
\hline 260 (C) Terrae Didat. & Campinas, SP & v.14 & n.3 & p. 256-262 & jul./set. 2018 \\
\hline
\end{tabular}


Figure 7 represents another interesting and useful case of a misleading illustration. It is supposed to depict a mummified rhinoceros found in a tar pond inside a cave at a certain location in Europe. Although we can accept that the author tried to simplify the actual situation, he has exaggerated. The sketch seems to represent a geological section through sedimentary layers. An anticline is present, with the upper part eroded, and it can be interpreted as a structural trap for the oil, gas and water supposedly present, as represented by the horizontal yellow, black and blue layers. Several interesting questions arise: Is there any reason for the corpse of the fossil to be found standing on the top of a folded layer? Are gas, oil and water filling a pre-existing void flanked by the upper and lower orange layers? Students may be encouraged to explore the web to find actual examples of animals fossilized in tar through a natural process of mummification. Visiting the website of the Rancho La Brea museum can be illuminating in correcting all the misconceptions present in the illustration of Figure $7 b$, but can also be an interesting experience of how a fossil site of primary importance has been incorporated into a growing city. It is worth mentioning that more than 600 species of animals and plants have been identified embedded in the tar deposits, which became active (as a natural oil seep) about 40,000 years ago, and even today, oil and gas are seeping up from the underground (Fig.8).

\section{The website}

Since none of the available platforms was found suitable for the proposal, an ad hoc one is being developed with the aid of an expert. This required a series of adjustments because the expert did not have knowledge about the project and the science involved, and the scientists in charge of this area did not have previous experience in this kind of task, so it took some time to develop a common language and start the core work. Most of the illustrations belong to the developers or have been taken from Creative Commons, in order not to have problems with copyrights. Each of the thematic sections covered in the website, one of which is Oil and Gas, has a Question and Answer, Additional Information and Teaching Resources entry. An important addition to the website is the development of a special entry, nicknamed "Science-catcher", which will use mobile phones and QR codes.

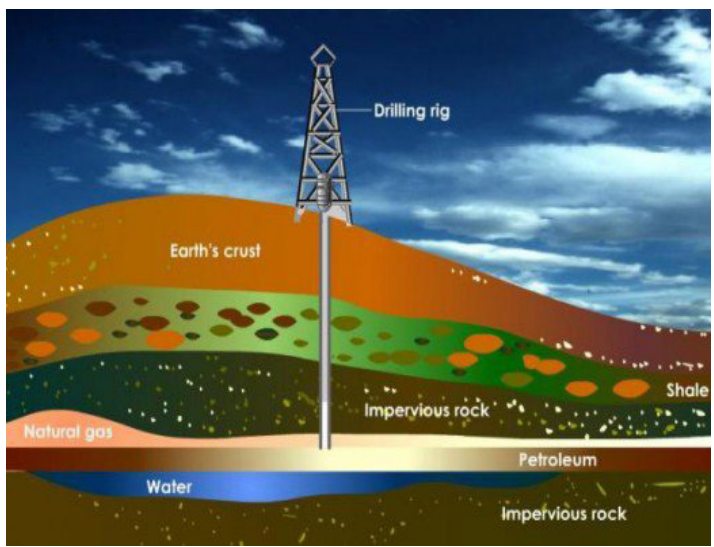

Figure 6. Errors and misconceptions are present in this representation of the geological features of an oil and gas field (https://usercontent2.hubstatic. com/7136969_f520.jpg)

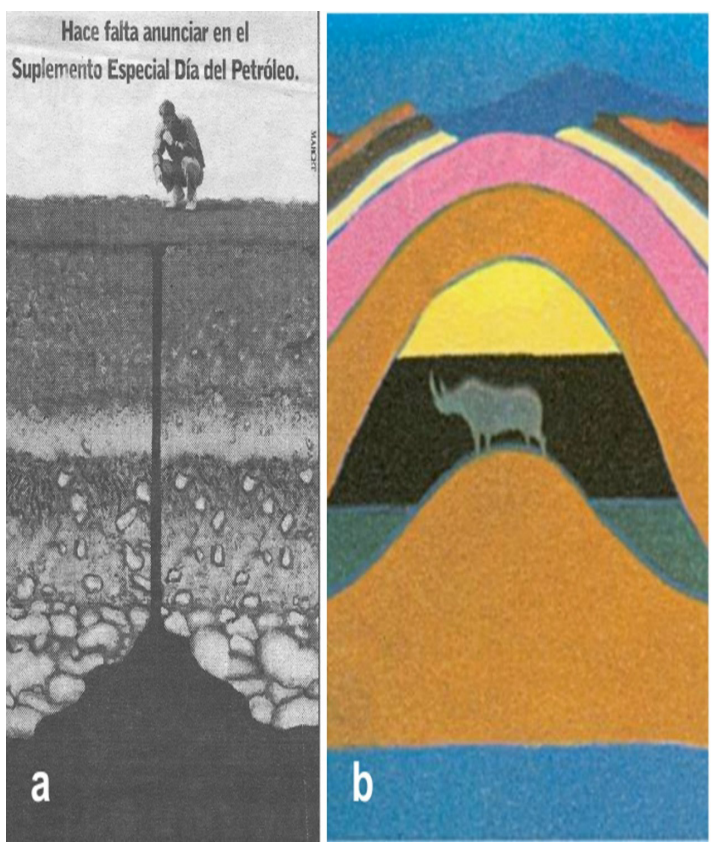

Figure 7. a. An illustration with scale and conceptual errors. b. A rhinoceros suddenly mummified when standing at the top of an anticlinal?

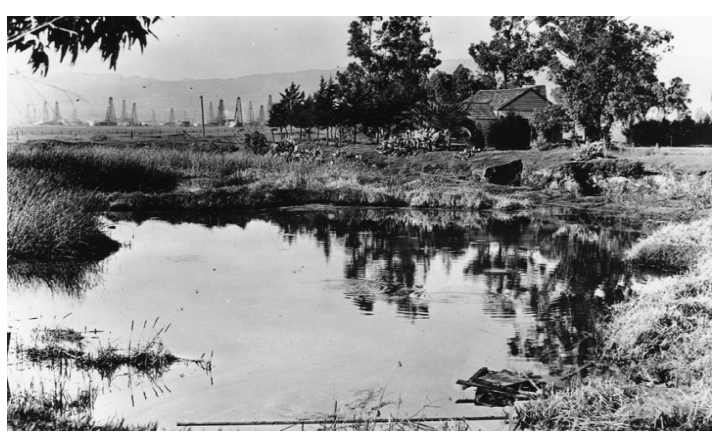

Figure 8. A panoramic view of Rancho La Brea at the beginning of the $20^{\text {th }}$ Century. Oil rigs may be seen in the background (Image: https://commons. wikimedia.org) 


\section{Acknowledgements}

The University of Buenos Aires, for the funds associated with the PDE07/2016 Project, and all those who, in one way or another, have put their grain of sand in this ripple, are sincerely acknowledged.

\section{References}

Sellés-Martínez, J. 2013. Informal Educational Strategies in Teaching Geosciences When For- mal Courses Are Unavailable: The Experience of AulaGEA in Buenos Aires, Argentina. J. Geosc. Educ., 61(1): 3-11.

Galagovsky, L. and Pérgola, M. 2017. Química en Contexto. Una experiencia didáctica basada en la adaptación del programa alemán Chemie im Kontext (ChiK) en España y Argentina. X Congreso Internacional de Investigación en Enseñanza de las Ciencias. Universidad de Sevilla, Sevilla, España, 5-8 de Setiembre de 2017. Enseñanza de las ciencias, Número extraordinario: 619-624. 